\title{
Adapting Elementary School Learning Innovation in Industrial Revolution 4.0
}

\author{
Endang Setyaningsih \\ History Departement \\ State University of Malang \\ Malang, Indonesia \\ endangsetya34@gmail.com
}

\begin{abstract}
The rapid of technology transformation with the development of digital technology, Artificial Intelligence, Smart Production or Internet of Thing, Blockchain, Driverless Vehicles, and Big Data in the Fourth Industrial Revolution spurred elementary school education institutions to educate the student graduated with the social ability to be adapted to technology. Parallel to the digital networking, production network and smart market innovation that include with technology refer at redefining the whole design of social study teaching learning and evaluation process in basic education. It is needed to prepare Indonesian young generation to compete in Industrial networking that fulfilled by automation job and Artificial Intelligence domination. .This research encompasses the basic innovation curriculum in social teaching learning for elementary school student to be respective to the Indonesian government innovation roadmap. The innovation learning integrating Smart Education System, Smart Literacy and creative innovation, Entrepreneur System, Smart Distance teaching, linking the Elementary School Student with education to create working opportunities earlier, attended to smart industry networking and build the ability to operate the Artificial Intelligence through smart phone. Elementary school curriculum innovation making optimism for young smart generation to be aware to compete and wise in disruptive technologies.
\end{abstract}

Keywords: learning innovation, education 4.0, smart literacy, disruptive technologies

\section{INTRODUCTION}

The rapid of technology transformation with the development of digital technology, Artificial Intelligence (AI), Smart Production or Internet of Thing (IoT), Blockchain, Driverless Vehicles, and Big Data in the Fourth Industrial Revolution (4IR) spurred elementary school education institutions to educate the student graduated with the social ability to be adapted to technology. Industrial revolution 4.0 is currently a prevalent term. The revolution are initiate by the advancement of technology in many aspect of life.
Moreofer, industrial revolution 4.0 is related to digital technology which humans are being gradually replaced by technology which humans are being gradually replaced by technology-based practices. McKinsey states that 52.6 million types of existing jobs will be substituted by technology-based practices as the result of industrial revolution 4.0. Humans, in the sense, may no longer have jobs as everything is run digitally. To cope with the situation, humans are required to equip themselves with highly refined skills and be mentally strong [1].

The global study of 46 countries and 800 occupations by McKinsey Global Institute found that up to one-fifth of the global work force has affected. Up to 800 million global workers will lose their jobs by 2030 and be replaced by robotic automation. Specialist lower wage jobs such as gardening, plumbing and care work, will also be less affected by automation. In developed countries, the need for university education will grow, as jobs that required less education shrink. In the United States (US) alone, 39 to 73 million jobs may be eliminated by 2013 , but about 20 millions of those displaced worker may be able to easily transfer to other industries. But the caution that new technology will yield new types of jobs, similar to the introduction of the personal computer in the 1980s which led to technology support work, and online business, McKinsay report [2].

The world is currently amidst a technological transformation that will fundamentally change the way we life and work. It is difficult to predict precisely how this transformation will impact different industries and countries. However, we know that this transformation is unlike anything we have seen before due to the sheer pace and breadth of these changes. Many see these as an ushering of new era of growth, change and opportunity [3].

Therefore to anticipate this digital networking as implication of 4.0 industrial revolution, Indonesian Government trough Industrial Minister Airlangga Hartarto are prepare to contend this inevitable challenge by launching an integrated roadmad Making Indonesia 4.0. To achieve this goal, this collaborative step needs to involve several stakeholders, from government 
Further in order to support the government effort to respond to the Republic of Indonesia 4.0, ITS determined 10 main strategies by on aligning thing. There are including Digitalpreneurship; Distance Learning; IT Infrastructure or Eservice on Smart Campuses; Lifelong Learning; Global Network Academic; Research and Innovation; IoT or Big Data; Intelligence Machine; Character Building 4.0; Teaching Industry; Alignment to Industry; and Public needs; Adaptive Environment to succeed the Indonesian government revolution Industry roadmad, (www.its.ac.id/news/2, 2018).

According to this, this research encompasses the basic innovation curriculum in social teaching learning for elementary school student to be respective to the Indonesian Government innovation roadmap. The innovation learning integrating smart education system, smart literacy and creative innovation, entrepreneur system, smart distance teaching, linking the elementary school student with education to create working opportunities earlier, attended to smart industry networking and build the ability to operate the artificial intelligence through smart phone.

This paper refers to several previous studies conducted by the improving quality of elementary school education. First introduces the technological nature of the 4IR, competencies required for elementary school student contexts of Indonesian basic education relating to the practical implementation of the 4IR preparedness. Then it analyses and compares similarities and differences of IT curricula of Indonesia elementary school to identify the trends in developing 4IR-relefant curricula in Indonesia. The analysis and comparison focus on big data, loT, AI curricula. The paper concludes with recommendations for education teachers to apply appropriate approaches in developing 4IR curricula for elementary school to better prepare a 4IR-ready workforce in the future[6].

Based on the topic, basic education is required to produce fresh graduates who can compete in the global era. The elementary education program, therefore, which aims to produce qualified teachers, needs to put forwards new literacy concepts in its class programs. Issues of literacy, currently are getting special attention from the Indonesian competitiveness is in a squate. The integration of new literacy concepts will equip students with high-level skills as literate people to cope with rapid changes in disruptive era [1].

\section{METHOD}

This research employed qualitative approach that means an approach in which data processing does not involve mathematical and statistical calculations but emphasizes interpretative studies. In addition, Cresswell on [1] explained if qualitative research is an inquiry process of understanding based on distinct methodological traditions of inquiry that explore a social or human problem the research builds a complex holistic picture, analysis words, report detailed informant, views, and
10 main strategies as an effort to adapt to the various influences of the 4.0 Industrial Revolution, 
conduct the study in a natural setting. This research involved literatures review type. Literature review is an activities relating to the method of collecting research materials from various literatures without requiring field research [1].

Another broad category of qualitative analysis is content analysis. The data for content analysis can take almost any form, including all types of written documents magazines, court proceedings, teacher's evaluations of students and audio or visual materials such as movies, television and advertisements. The goal of qualitative content analysis is to examine both the manifest content of an item, what is actually recorded or depicted, and the latent content. Latent content refers to the subtle messages or meaning encoded in an item, such as the unspoken assumptions that give the content meaning in the social world[7].

This research produce scientific reasoning ideas from the result of literature review and the results of the researches views about topic of research. This research examines elementary education literacy in era industrial revolution 4.0. The technique of collecting data in this research used document analysis. Document analyzed in this research consist of research journals, literature journals, and seminar reports. On the other hand, researcher collected data by reading, organizing topics, and recording important information on references [1].

\section{RESULTS AND DISCUSSION}

4IR technologies such as artificial intelligence, autonomous vehicles and drones, the internet of thing (IoT), 3D printing and biotechnology are particculary relevant many are alredy showing promise at reshaping urban sectors including transport, energy, waste, water and buildings-and change will only accelerate [3]. In industrial revolution 4.0, the relationship between human life and technology become more multifaceted. Human can exploit technology more than they presently perform as it is still categorized as small-scalle utilization[1]. Sustainability challenges, including climate change, loss of biodiversity, proverity, epidemics, and violent conflicts, manifest at specific locations; yet the undelying causes are linked to ther regions, nation, and even the global society[8].

Beside that Budnar et.,al 2011 in [9] says, A total of 175 hours of class time in primary school are dedicated to it-70 in the 4th grade and 105 in the 5th grade. The didactic recommendation for teaching of the subject social studies suggest that teacher should derive from student's prior knowledge, skill and interest, and take into account their individual potention when they plan lesson. With this new teaching challenges, teacher must determine how to best equip student with these competencies.

The classroom exercise should present suistanability problems and solutions options are an important part of such as a competence focused approach. These classroom exercise, however, lack the cross cultural and real world experience that is critical for developing competencies that account for the local nuance of sustainability problem and solutions [8].

\section{A. The Content of New Elementary School Curriculum in line by $4 I R$}

The most of the world conventional education systems has not be adapting to the rapid development of working life. According to some research show, many employers do not have the technical staff with the application skills they demand. According to a field assessment of McKinsey with employers and newly graduated people, approximately $40 \%$ of employers show a lack of skills as the primary reason for not being able to find people suitable for basic jobs. Curriculum elementary school till undergraduate need to be reaudited so that they can keep pace with the rapidly changing Industry conditions in recent years[10].

Based from chart of Comparison of Top 200 Universities, Global Competitiveness Index, Happy Plant Index and Worldwide Educating for the Future Index analysis at [11] we know that shows the current status but its policy, ultimate resource (teachers), openness and freedom must be aligned with the future needs if they want to keep and improve their future competitiveness. Competitiveness and happiness can co-exist if our education system is properly designed. Including the elementary school institution. The establishment of an education system and renewal of the curriculum is absolutely necessary in order to prepare our young generation in the disruptive era and highly human potential facing the automation.

\section{1) Entrepreneur Insight}

New curriculum will focus on effort to develop basic entrepreneur insight trough curriculum alignment. Digital coworking space empowerment, connecting with funding sources and markets for economic start up as well as providing digital market place innovation. Entrepreneurship is one of the most import ant preconditions for economic development. Entrepreneurship education at all levels of formal and nonformal education is an essential element of the entrepreneurial ecosystem in the developed economies of the world. Entrepreneurial ecosystem are defined as a set of independent actors and factor coordinated in such a way that they enable productive entrepreneurship within a particular territory. The era of automation necessitates the development of not only digital, but also social and emotional skills[12].

Stamp \& Spigel, 2016 at [12] Modern education is one of the most important preconditions for economic development. Entrepreneurship education at all levels of formal and nonformal education is an essential element of the entrepreneurial ecosystem in the developed economies of the world. Entrepreneurial ecosystems are defined as a set of interdependent actors and factors coordinated in such a way that they enable productive entrepreneurship within a particular territory The era of automation necessitates the development of not only digital, but also social and emotional skills [12]. 
Kisić \& Petković, 2019 at [12] said that development of creativity, innovation, analytical and critical thinking, communication, negotiation and decision-making skills are gaining in importance. These skills, an integral part of entrepreneurship competence, are developed through entrepreneurship education. Entrepreneurship education is taken to cover all educational activities that seek to prepare people to be responsible, enterprising individuals who have the skills, knowledge and attitudes needed to prepare them to achieve the goals they set for themselves to live a fulfilled life[13]. Entrepreneurship education leads to higher employability (European Commission, 2015). Economies based on natural resources and productivity are not dominant economies in the era of the fourth industrial revolution. The strongest world economies are economies based on knowledge and innovation. "The entrepreneurship ecosystem is strongest [12].

\section{2) Internet of Thing (IoT)}

Internet of things (loT) are being adopted for industrial and manufacturing applications such as manufacturing automation, remote machine diagnostics, prognostic, health management of industrial machines and supply chain management cloud based manufacturing is a recent on-demand model of manufacturing that is leveraging loT technologies[14]

The IoT given that physical engagement increases involvement in learning and aughmented classrooms has shown to pique student interest, this technology would enhance learning capability. Traditional class could be redesigned by arming them smart board, virtual reality headset, or augmented reality (Wu et al., 2013) at[11]. Smart board can replace book and writing utensils or overhead projectors and allow teacher to enhance their lessons by integrating computer, video, cameras, virtual game base on smartphone, and online resource.

Beside smart board, Virtual Reality (VR) technology let's student explore ideas, play games, views film, visual complex data, interact with $3 \mathrm{D}$ object that too small or microscopic size[11]. Teacher can use IoT technology to monitor student's learning in other ways, all of which could be computer automated and presented to teacher in an effected manner.

Jhon Jenning, at Hot Take Automated Classroom resulted that automation in classroom needed to be taken. The teachers should never feel like they have limited options in classroom because procedural roadblocks or inefficiencies. A modern student information system should provide an automated notification workflow for discipline, attendance, and grades that includes the teacher, central office, and parents where appreciate.

Then Jennings explain that the benefits of such a workflow are twofold. First it can spent drafting emails, repeating details, and following up on consequences can be reinvested in personal instruction and communication with student. The secondly, information relayed as it is happening, eliminating that gaps and delays that plagued the old approach. When the teacher enter a grade or an incident record, they can have the peace of mind that all parties are being informed with one 'clik, and depending on security configurations. All of the documentation will be made automatically available to those who need access to it.

\section{3) Smart Literacy System}

During their school years, children and young people continue to learn and refine their communication skills. At their school student will create and make sense of a range of written, visual and spoken texts. To succeed in all learning areas, students need literacy skills and knowledge to understand, analyse, interpret and evaluate information, develop and express ideas and opinions, interact with others and participate in activities at school. To become effective learners, students need to be confident and motivated to use their literacy skills broadly. This can be observed when they: manage their own learning to be self-sufficient, work harmoniously with others, are open to ideas, opinions and texts from and about diverse cultures, return to tasks to improve and enhance their work, are prepared to question the meanings and assumptions in texts (https://www.education.sa.gov.au).

Freire \& Macedo, 1987 in [15] said, Literacy becomes a meaningfull construct to be degree that it is viewed as set of practice that function to either power or disempower people. Literacy system that are integrated with technological sophistication are needed to support the formation of modern school design including one language elementary school or international schools. But based on several studies knows that student of elementary school by single languages have faster adaptation to the development of the literacy era compare by bilingual school that are constrained with language skill.

Literacy skills teach the children about new knowledge and adaptability to change, the ability to harmonize multicultural cultures and differences languages. So because of smart literacy system implementation the world become open and easy to get through with it. In the digital age, information can be disseminated through a variety of media besides hard copy of journal. The traditional role of library which is considered as an institutions of information supply with a specific information structure that operates as an intermediary between supply and demand on diverse (Information) markets[11]. Technological advances have enhanced education to new height, where some school institutions can afford to upgrade their facilities, including smart libraries[11] that adapted to modern technology.

Technological innovations generate constant change and challenges in the information environment. In daily practice, the blended librarian must adapt to those phenomena[16]. Because Price \& Rogers, 2004 at [11] said that on small scale, the Internet of Thing (IoT) allows physical learning space to be digitally augmented, not exception to modern library as a source of smart literacy system. Given that physical engagement increase involvement in learning, and augmented classrooms 
have shown to pique student's interest. So this technology should enhance the literacy scale -capability. Traditional libraries must be redesigned by some facilities who support to digital literacy and smart communication.

The continuous emerge of new means of educational communication Makes library and librarian as a component of smart literacy system redesign learning common space and areas in order to attract more users. They are experiencing a transition of form and formats in which user access, store, recover and use of information, once basically printed, is abundantly digital today[16].

Therefore we urge that teachers, as part of the educational institution must advocate for multicultural and multilingual literature as part of the public school's literacy culture. In order for bicultural and bilingual student to succeed on high level educations[15].

Based on research we show that Literacy has a very important role in the public school to give power to bicultural and bilingual student, so they can maintaining a sense of cultural, language, and identity balance between their home culture and the dominant culture. Bi cultural and bilingual student have struggled to make a connection through public school literacy program that have been washed to remove cultural identity[15].

Goodman, Goodman and Flores (1984) in [15] concluded their research on literacy and biliteracy issues for reading and writing in bilingual education:

If school is relevant, if its curriculum and goals are consistent with the functional needs of the pupils, if it accepts their languages and culture and builds on it, then children will respond to school and grow. But if the school is irrelevant and insensitive, the pupils will only make whathever minimal accommodations they can to its demands.

Noh,Y (2015) in [11] suggested that a library 4.0 model based on the development of Web4.0. He posited that library 4.0. must include not only software-based approached but also technological environment such as maker space, Google class, context aware technology, digitalization content, big data, cloud computing and augment reality. But maybe it is impossible to implementing all of high level technology system in Indonesian traditional elementary school such as large amount of sub urbans and village area. So we can use a mobile smart phone robotic system that most of people use.

\section{4) Automate Classroom}

From the end of the 20th century through the modern days, classrooms have been littered with dials, switches, and drawers full of remote controle for various forms of media that may not see any use throughout the course of the year. Automated classrooms have evolved to simplify technology for even the most technophobic of teachers (Jhon Jenning, www.skyward.com). By automating the classrom's hardware via an intuitive interface, we can all about guarantee that the teachers will use their high tech tools more often and with greather efficiency.

This advance intergration of physical resources will also reduce the number training hours that need to be allocated for theacher and keep your IT eam from getting bogged down in service calls. Automated control system can be serviced remotely, thus mitigating the disruption presented by in-site troubleshooting.

In the event of an emergency, there is no time to waste. Automate school security system not only cut down on manual procedures, they can also save lives. An effective security system should be able to leverage your existing hardware into one, tightly integrated and easily accessible solution.

Then Jhon Jenning explained, that the phrase "automated classroom" can be intimidating and even offensive when taken out of context. It is important to point out that purpose of automation is not to replace teachers with robots or creative expression with artificial intelligence. It is solely to support teachers and students in pursuit a safer and more productive learning environment. You will find that, when automation technology is implemented correctly, upfront costs administrative efficiently, and student outcomes.

Lastly, classrooms can be augmented with computergenerated stimulus that appear in reality, namely augmented reality (AR) trough their smartphone cameras. AR merges reality with fake stimuli to enhance learning; data appear over reality so student can observe artificial images in a real-world setting. There are currently AR apps for almost any subject, such as geometry, translation, math, and art. For insurance, user of the free Google translate app can translate text into other languages in real-time by capturing the text on their smartphone[11].

Together, digitally augmented classroom strengthen learning capacity, happiness, and competitiveness of universities. Admittedly, incorporating these technologies is costly and time intensive but the investment bring long-term benefits. Traditional classroom can be replaced by online courses, but augmented classroom cannot be. While augmenting digital classroom is one way smart campus can assists education, smart campuses enhance learning in other ways as well[11].

\section{5) Lifelong Learning and Learning Together}

Lifelong learning, provides a lifelong learning system that enables more flexible academic and competency strengthening. Not only for elementary school students, but also for the general public so as to increase national human relationship competitiveness. This strengthening is not only through academic programs by setting up a more flexible education system, but also in training and apprenticeships in an effort to strengthen skills and competencies. 
The Learning Together approach to working with families successful engagement with families and children occurs when educators apply the following thing, 1) Recognise and respect that families want the best for their children. 2) Recognise that all families are different and are respectful of the differences. 3) Recognise that all families have strengths. 4) Develop relationships with families that are characterised by building on the strengths of each other's knowledge. 5) Use a strengths approach including power with rather than power over. 6) Engage in co-construction processes through developing partnerships with families. 7) Actively support families to recognise and grow aspirations for themselves and their children. 8) Understand that powerful learning happens in the everyday. 9) Actively engage in reflective practices together and with families to support quality service provision [17].

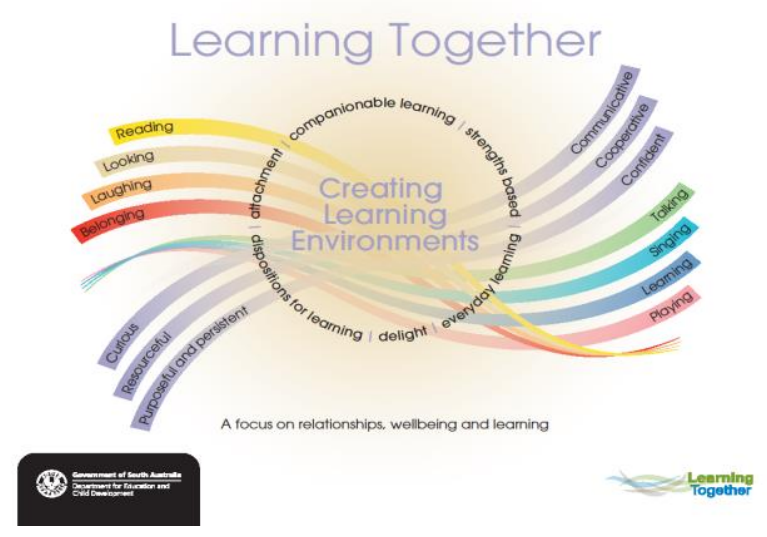

Fig. 1. A Focus on relationship, wellbeing and learning as from [18]

The picture describe a focus on relationship, wellbeing and learning in the scope of learning together. Interaction between parents and their children is a major focus of the Learning Together. Learning Together managers support parent and child interactions by: working individually with families, modelling, providing an environment and resources for interactions, and providing a framework for parents to observe their children's learning.

\section{6) Global Network Community}

Digital technology is fast becoming the core of life, work, culture and identity in Indonesia. Lipman, (2012) in [19] observe 2016 Indonesia had 76 million Facebook users, the fourth highest number in the world. Jakarta has been named the world's 'most active city on twitter'. It does not only influence the adult digital media user but a significant portion of the users are the elementary school till after graduate age.

The number of smartphone users worldwide has reached 2.5 billion, which is equivalent to $33 \%$ of the world population. The annual $10 \%$ growth rate of smartphone users since 2014 has triggered the fast growth of mobile applications (apps) [20]. Smartphone users not only cover most of adults and academic graduate but including through elementary school-age student. It is not belong to expensive or rare technology product at this era.

In the last couple decades, there have been rapid developments in the fields of mobile technologies, data acquisition and data analytics. The number of mobile phone users all over the world has increased tremendously over the last decade. In some countries, the number of mobile phones exceeds the population. With the advent of smartphones, crowd sourcing has been made possible. Likewise, data acquisition and analysis techniques have evolved rapidly with the swift increase in processing capabilities. We surveyed the technologies that had been developed in the last two decades that are now being used in making our everyday driving and travel experience[20].

Research and Basic Innovation Developer approve basic research and innovation strengthening elementary school student to increasingly the new method of learning such us internet web and smartphone. Manoj Kumar at [21] explained the sharp rise in the number of literate youth, the expansion of education as a field, the reduction of telecom call rates, the rise in consumer income and the socio-economic changes have increased the demand for internet sharply in the past decade in India.

Manoj Kumar also mentioned the World Wide Web is host to an ever expanding information explosion. In the absence of quality teachers and enriched libraries, the students demand for surfing the internet for educational purposes has seen a sharp rise. Several institutions have started to provide online study material through their websites. Use of internet in education has a potential to revolutionize the way we live our lives. Students also usually connect their mobile phones to their laptop/desktop to access the internet. Hence we observe that there already exists a consumer behaviour that is conducive to the digitization of distance learning initiatives [21]

\section{7) Artificial Intelligence Guidance}

The economic competitiveness is tied to be better competence of the workforce and fast implementation of new technologies. This requires new approach for formal and nonformal education. We purpose a new robotics learning concept and collaboration scheme to support and correlated the education with industry[22]. Innovative technologies emerging from industrial revolutions have been the result of some professional groups and have led to the emergence of new bussinees lines [10].

The application of robotic systems which addresses fundamental issues in coexistence of surveillance and robots from psychological and philosophical aspects over interaction and communication mechanisms of architectures and technological systems is popular nowadays [22]. In these materials, not only wireless networks were applied in these proposed systems but also mobile vehicles were considered to 
play a role as the carriers of other devices for many applications. Most of all, the vision feedback becomes a crucial element in these systems. Along with gradual development of the fundamental capabilities of smartphone, it grows from the basic communication tools to the remote controllers which now are not only able to communicate with others but also able to control devices in distance. The wireless network inbuilt in the smartphone, such as $\mathrm{Wi}-\mathrm{Fi}$ and Bluetooth systems, realizes many ideas feasible and makes smartphone play an important role in the whole system than ever since. Among these wireless communication systems, Wi-Fi system is the most popular wireless network with successful applications of combining the robotic systems.

\section{8) Moral and Character Building 4.0.}

Character building 4.0, equipping Elementary school graduates with intelligent, trustworthy and creative characters including effort to improve $5 \mathrm{C}$ aspect of learning. It is creative, cognitive, collaborative, competence, and cohesiveness. As might be expected, values education and moral educations began to reflect these changes in society. Instead of simply inculturating and modelling values, educators were now encouraged to help student clarify, their own values, learn higher level of morals reasoning, and lead the skills of value analysis[23].

A. Kamaruddin S.(2012) at[24] explained character building of students in each educational environment means the efforts made by the institution in the context of the formation of the character of students. The term is synonymous with coaching is the formation or development. Associated with educational institutions, now more encouraged the formation of the school culture. One of the chosen school culture is a culture of noble character. From this came the term the formation of moral values in the school culture.

Furthermore A. Kamaruddin suggest to educational institutions about the necessary of rebuild character educational for the student as a goal of the accademical competencies:

Character education is important for the growth of a human individual as a whole and should be done early. But that does not mean if you do not accommodate basic education of character building, educational institutions also felt no need to conduct it. It is important for an educational institution to not only pay attention to the needs of the academic competence of students, but also the character development so that graduates become graduates who are prepared academically and good character. The desire to build the character of students have poured into the strategic planning and program design in a systematic and integrated. Results from this program does not directly alter the character of the students, but it is expected to give a positive color in an atmosphere of learning.

And the last of his result conclusion he states, the future, the design of character education should be done with high commitment and continuous improvement of business done. Familiarization character (character) needs to be done and the realization of noble character (character) noble ultimate goal of an educational process so coveted by every institution that organizes the educational process. Culture or cultures that exist in institutions, schools, colleges, and others, was instrumental in establishing good moral values among the academic community and its employees. Therefore, educational institutions have a duty and responsibility to conduct moral education[24].

\section{9) Smart Curricula Alignment to Industry}

Most of business enterprises are engaged in strategic planning by using new ideas, objects, practices and reaching the goals. Generally, strategy is a simple way to analyze the current situation of the organization, expected future situation, the right direction confidently and achieving the objects of the organization. Actually, it is more than that which provides the systematic way for identifying and evaluating factors external to the firm and fixing them with the organization's abilities. In addition, strategy is a long process over long time periods with individual resources within a competitive environment to meet customer needs.

In other words, strategy is a method or process of direction and a scope of an organization to achieve opportunities with its pattern of resources and meet the demand of markets and stakeholder expectations. A company's strategy can decide the fate of an organization, help them to create innovative products and sustain their competitive advantage[25].

Mintzberg at [25] emphasizes this broad diversity of perspectives in the current debate and has identified ten main distinct schools in strategic thinking. Three of these schools design, Planning and Positioning School fall under the prescriptive school and the other seven schools Entrepreneurial, Cognitive, Learning, Political, Cultural and Environmental School are descriptive in nature. As with any classification, there is a certain danger in the sense that trying to put rich individual ideas and concepts into a limited number of "boxes" which may lead to oversimplification. However, this classification of strategy schools does contribute to a deeper under- standing of how strategy, systems are perceived in a limited number of the mainstreams of thinking. Ten deeply embedded, though narrow, concepts typically dominate current thinking on strategy[25].

Among the schools of thought on strategy formation, one in particular underlies almost all prescriptions in the field. Referred to as the "design school", it proposes a simple model that views the process as one of design to achieve an essential fit between external threat and opportunity and internal distinctive competence. The design school therefore proposes a model of strategy making that seeks to attain a match, or fit, between internal capabilities and external possibilities. In the words of this school's best-known proponents, "Economic strategy will be seen as the match between qualifications and opportunity that positions a firm in its environment". Design School has an 
important and influential contribution in developing other schools of thoughts and providing a foundation to strategic management principles[25].

\section{0) Adaptive Environment Mindset}

Every young generation must be changing the mindset natural environment sustainable future. Because it is very necessary to balancing between cities and the natural environment from resource use and ecosystem service to pollution. In emerging cities, action to address the following key challenges will be particularly important for delivering environmental sustainability

The impact of Technology in our Society and in particular in Education is an ongoing and critical task. C. Ochoa in [13] said, there's also a huge disparity when it comes to technology access, whether due to socioeconomic factors, lack of resources, infrastructures development, knowledge and budget. I think it is needed a seriously debate about these crucial issues for the future development of our society. Maybe it is time for "Reimagining the future of Education", based on lessons learned, past experiences and future demands.

He also state about the real environment world problems, that must give them real-world problems to solve:

Let's imagining for a while we were "Teleported" into the "Year 2025". close your eyes and try to "imagine" how it looks like. Think about it for a minute. We can imagine a futuristic picture of the world, but all our pictures are different. Our imagination is restricted by our education, knowledge, background, and social environment. But our creativity has no limits [13]. Try once again with an open mind, trying to reimage the space, the planet, our city; our hometown. will be something like a: "Smart World 2020" scenario. Think about the new society needs and demands, the new citizen's skills, the environmental challenges, the new Smart Ecosystems, the Internet of Things implications, the eHealth and Well-Being ecosystem. And now, try to find for the best answers to your futuristic vision of the world. Do you really think we are on the right track? "If we wish to prepare a generation of citizens, entrepreneurs and leaders for the 21th. century who can face real-world problems, we must give them real-world problems to solve".

The future framework for smart digital education, leave permanently redefined from the impact of new technologies, communications and infrastructures development, experiences and case studies. And last but not least, all global experiences from a more interconnected perspective. We are talking about the "Future of the Society". We have a unique opportunity to harness this 4IR, and the societal shifts it triggers, to help address environmental issues and redesign how we manage our shared global environment. The 4IR could, however, also exacerbate existing threats to environmental security or create entirely new risks that will need to be considered and managed[13].

\section{CONCLUSION}

Elementary school curriculum innovation making optimism for young smart generation to be aware to compete and wise in disruptive technologies. To response the impact of Technology in our Society and in particular in Education is an ongoing and critical task, character education is important for the growth of a human individual as a whole and should be done early. The desire to build the character of students have poured into the strategic planning and program design in a systematic and integrated.

\section{REFERENCES}

[1] [1] R. Rahman, A. W. Sakti, R. N. Widya, and R. Yugafiati, "Elementary Education Literacy in the Era of Industrial Revolution 4.0," 2019.

[2] [2] "Technology, jobs, and the future of work 2 McKinsey Global Institute."

[3] [3] "The Fourth Industrial Revolution Impact to The Future of Sustainable Urban Development in Malaysia by DR. Azmizam Abdul Rasyid Director of Knowledge Management and Advisory URBANICE MALAYSIA (Urban Wellbeing Centre of Excellence) Ministry of Urban Wellbeing, Housing and Local Government."

[4] [4] Kementerian Perindustrian, "Indonesia's Fourth Industrial Revolution Making Indonesia - Making Indonesia 4.0," Kementeri. Perindustrian, pp. 24-27, 2018.

[5] [5] J. D. Geddes, A. R. Murrell, and J. Bauguss, "Childhood Learning: An Examination of Ability and Attitudes toward School," Creat. Educ., vol. 01, no. 03, pp. 170-183, Jan. 2011.

[6] [6] T. T. B. Lieu, N. H. Duc, N. W. Gleason, D. T. Hai, and N. D. Tam, "Approaches in Developing Undergraduate IT Engineering Curriculum for the Fourth Industrial Revolution in Malaysia and Vietnam," Creat. Educ., vol. 09, no. 16, pp. 2752-2772, 2018.

[7] [7] B. Kawulich, "Qualitative Data Analysis Techniques," Conf. RC33, no. January 2004, pp. 96-113, 2004.

[8] [8] A. Wiek, M. J. Bernstein, M. Laubichler, G. Caniglia, B. Minteer, and D. J. Lang, "A Global Classroom for International Sustainability Education,” Creat. Educ., vol. 04, no. 04, pp. 19-28, Apr. 2013.

[9] [9] P. Jančič and V. Hus, "Didactic Games in Social Studies in Primary School," Creat. Educ., vol. 08, no. 12, pp. 1892-1902, Sep. 2017.

[10] [10] A. Durmus and A. Dağl1, "International Journal of Multidisciplinary Studies and Innovative Technologies Volume : 1 Number: 1 Year: 2017 Pages: 1-3 Integration of Vocational Schools to Industry 4.0 by Updating Curriculum and Programs +."

[11] [11] H. C. Y. Chan and L. Chan, "Smart Library and Smart Campus," J. Serv. Sci. Manag., vol. 11, no. 06, pp. 543-564, 2018.

[12] [12] S. Petković and S. Kisić, "The Necessity of Building Entrepreneurial Ecosystems in The Educational System of Small PostTransition developing economies for the fourth industrial revolution," j. Contemp. Econ., vol. 1, no. 1, may 2019.

[13] [13] C. J. Ochoa, "Virtual and Augmented Reality in Education" in ICERI2016 Proceedings, 2016.

[14] [14] A. Bahga and V. K. Madisetti, "Blockchain Platform for Industrial Internet of Things," J. Softw. Eng. Appl., vol. 09, no. 10, pp. 533-546, Oct. 2016.

[15] [15] Y. J. Thao, "Bicultural Literacy Curriculum," Creat. Educ., vol. 03, no. 02, pp. 251-255, Apr. 2012.

[16] [16] G. A. T. Vargas, E. J. S. Vanderkast, A. A. R. García, and J. T. G. González, "The Blended Librarian and the Disruptive Technological 
Studies: Indian Perspective,” Int. J. Manag. Inf. Technol., vol. 3, no. 3, Innovation in the Digital World," OALib, vol. 02, no. 08, pp. 1-9, Aug. 2015.

[17] [17] D. K. Novins, "Learning Together," Journal of the American Academy of Child and Adolescent Psychiatry. 2018.

[18] [18] Decd, "The Learning Together approach to working with families Learning Together."

[19] [19] E. Jurriëns and R. Tapsell, "Challenges and opportunities of the digital 'revolution' in Indonesia," Digit. Indones. Connect. Divergence, vol. 2020, no. Pratama 2016, pp. 275-288, 2017.

[20] [20] K. Tao and P. Edmunds, "Mobile APPs and Global Markets," Theor. Econ. Lett., vol. 08, no. 08, pp. 1510-1524, 2018.

[21] [21] Manoj Kumar, "Impact of the Evolution of Smart Phones in Education Technology and its Application in Technical and Professional pp. 39-49, 2011.

[22] [22] M. Lanz, R. Pieters, and R. Ghabcheloo, "Learning environment for robotics education and industry-academia collaboration," in Procedia Manufacturing, 2019, vol. 31, pp. 79-84.

[23] [23] H. Kirschenbaum, "A Comprehensive Model For Values Education And Moral Education," Tạp chí Nghiên cứu dân tộc, 2019.

[24] [24] S. A. Kamaruddin, "Character Education and Students Social Behavior," J. Educ. Learn., vol. 6, no. 4, p. 223, 2012.

[25] A. Sarbah and D. Otu-Nyarko, "An Overview of the Design School of Strategic Management (Strategy Formulation as a Process of Conception)," Open J. Bus. Manag., vol. 02, no. 03, pp. 231-249, Jul. 2014 